\title{
Planejamento e razão instrumental: uma análise da produção teórica sobre planejamento estratégico em saúde, nos anos noventa, no Brasil
}

\author{
Planning and instrumental rationality: \\ an analysis of theoretical production in strategic \\ health planning in the 1990s in Brazil
}

\footnotetext{
1 Departamento de Medicina Preventiva e Social,

Faculdade de Ciências Médicas, Universi dade Estadual de Campinas. Rua Américo de Campos 93 Campinas, SP

13083-040, Brasil.

rosanaoc@mpc.com.br
}

Abstract This articleanalyzes recent theoretical production in Brazil on strategic health planning, focusing on instrumental logic. The approach centers on authors who have emphasized theoretical and methodological aspects of strategic planning. Emphasi s is on the need to develop a new instrumentality capable of answering dilemmatic questi ons faced in health issues (professional health workers' efficacy/personal achievement) in order to recover the teleological planning action. The author provides a proposal that consi ders planning a modulator for the incorporation of technology by heal th institutions.

Key words Planning Techniques; Health Planning; Planning; Public Health

Resumo Este trabalho analisa uma parte da produção teórica, no Brasil, concernente ao Planejamento Estratégico à luz da crítica à razão instrumental. O recorte está focado em autores que, na década de noventa, centraram sua produção na elaboração teórico-metodológica. Enfatiza-se a necessi dade de construir al guma nova instrumental i dade capaz de dar conta do di lema efi cácia/real ização pessoal dos trabal hadores, considerado central para as institui ções públicas de saúde, resgatando a ação tel eológi ca do planejamento. Propõe-se pensar o Planejamento como modulador de incorporação tecnológica em instituições de saúde.

Palavras-chave Técnicas de Planejamento; Planejamento em Saúde; Planejamento; Saúde Pública 
O problema do planejamento em saúde no fim do século

O objeto de estudo deste artigo é a produção de teorias e métodos de planejamento em saúde. Limitamo-nos a analisar a produção recente de alguns autores brasileiros que - ao tomarem, como eixo, a questão do Planejamento Estratégico - elaboraram propostas teórico-metodológicas, não se restringindo a aplicar metodologias já existentes. Por isso, não foram incluídos outros autores que também oferecem contribuições do ponto de vista da difusão de métodos e legitimação da área do Planejamento na Saúde Coletiva Brasileira (Paim, 1992; Teixeira, 1995). A citação de todos excederia os limites deste trabalho.

Ponderamos que o Planejamento - "Ato ou efeito de planejar; Trabal ho de preparação para qual quer empreendimento, segundo rotei ro e métodos determinados (...); Elaboração, por etapas, com bases técni cas de planos e programas com objetivos defini dos" (Ferreira, 1997) somente terá valor de uso se não perder sua capacidade instrumental. É campo metodológico que visa os meios como seu fim. Sua razão de existir é, e será, operacionalizar organizações e grupos para atingir fins; em razão disso, defendemos que é o método dos meios por excelência.

Esta questão coloca o Planejamento dos anos noventa em meio a um dilema fundamental: como fugir do papel controlador, advindo da razão instrumental, sem perder a própria instrumentalidade, não deixando de ter valor de uso.

Semel hante dilema está presente nos autores que analisamos: quem tentou problematizar, com ênfase, a questão da razão instrumental, nem sempre conseguiu se avizinhar de nova metodologia; quem inovou mais na questão metodológica, não conseguiu se aproximar criticamente da razão instrumental nem questionar o caráter controlador do planejamento sobre trabalhadores e grupos.

Tentamos fazer a leitura crítica de alguns autores, encarando a crise do Planejamento com uma hipótese central: a crise do Planejamento, neste fim demilênio, éuma crise de seu relacionamento com a racional idade instrumental. Isto porque foi neste fim de século que a crítica da razão instrumental voltou à pauta, depois de ter sido relegada, durante al gumas décadas, aos espaços periféricos das análises políticosociais.

A crítica do referencial estrutural-marxista e a queda do socialismo real, no final dos anos oitenta, recolocou a questão da subjetividade no foco das correntes preocupadas com as organizações (Morgan, 1996). Mas o trânsito entre esses dois pólos não tem sido fácil: enfatiza-se, nas análises, um ou outro ponto de vista. Consideramos que se trata de falsa dicotomia entre instrumentalização e subjetivação. Dicotomia que nós, planejadores, deveremos enfrentar e questionar, se quisermos atingir a vocação teleológica da área.

Referencial teórico: a razão instrumental ou a razão como instrumento?

É em Horkheimer \& Adorno (1989) que podem ser encontradas as reflexões mais críticas a respeito do "pensamento cegamente pragmatizado" como a nova mitologia da modernidade; 0 pensamento que teria perdido seu caráter crítico e sua relação com a verdade e, para o qual, "A natureza desqualificada torna-se o material caótico de uma simples classificação" (Horkheimer \& Adorno, 1989:8).

Para esses autores, somente a arte e o prazer escapariam do imperativo de prestar contas no mundo administrado: “(...) para o positivismo, que ocupou o posto dejuiz da razão esclarecida, uma digressão pel os mundos intel igíveis não é apenas mais proibida, mas é vista como uma tagarelice sem sentido" (Horkheimer \& Adorno, 1989:19). Nessa perspectiva, o pensamento só pode ser legitimado como redução ao formalismo lógico, "a subordinação dócil da razão aos achados imediatos" (Horkheimer \& Adorno, 1989:19). Nesse processo, sujeito e objeto tornam-se nulos e a operação entre espírito e mundo é resolvida sem deixar resto. $O$ passado é expulso e colocado à disposição do agora a título de saber praticável. Em contrapartida, esses autores propõem pensar os dados “(...) como superfície, como momentos mediatizados do concei to que só se preenchem no desdobramento de seu sentido social, histórico, humano (...)" (Horkheimer \& Adorno, 1989:19). A análise que fazem do mundo contemporâneo, procura no lluminismo a raiz do sistema de dominação do trabalho e da reprodução das relações sociais de poder estabelecidas.

Horkheimer \& Adorno (1989) buscam, no relato homérico da Odisséia, o entrelaçamento entre mito, trabalho e dominação. Quando Ulisses estabelece a divisão do trabalho em seu barco para resistir às sereias, estabelece os primórdios da ordem social: o dono, que faz os outros trabal harem para ele, assumirá o risco de escutar o canto mágico. Já seus companheiros, com as orelhas tampadas com cera, nada sabem da beleza do canto das sereias, só conhe- 
cem o perigo que implica. Fiéis ao seu papel social, reproduzem a vida do opressor ao mesmo tempo que a sua própria. A tentação é neutralizada em puro objeto de contemplação, em arte. O prazer é separado, para sempre, do mundo do trabalho.

Hoje assistimos à colonização do senso comum, resultante da hegemonia do positivismo no mundo científico, e à rendição da humanidade ao reinado do mundo prático, administrado. A técnica alarga seu espaço até ocupar o posto da teoria, e os métodos dos "meios" são transformados em "fins" em si mesmos.

É nesta linha de crítica que nos propomos a fazer a leitura dos autores brasileiros contemporâneos que problematizaram o Planejamento. Mas, quando se trata de pessoas e instituições, enfrentar a questão da razão instrumental só resolve parte do problema: com qual ou quais razões se deve repensar uma metodologia de Planejamento? As questões humanas e do mundo social nunca poderiam ser reduzidas ao mundo racional. Faz-se necessário ampliar o referencial teórico.

Segundo outros autores (Benasayag $\&$ Charlton, 1993), estamos diante de duas grandes rupturas, na época contemporânea. A primeira foi estabelecida pelo marxismo, ao anunciar que não existe o bem comum "em si", que ele é contraditório e conflitivo no devir dos processos. Segundo essa leitura, as amarrações estariam determinadas por dada estrutura social de produção. Todavia, para o marxismo e várias das correntes estrutural istas, existe a possibilidade de um agir racional: o agir do raciocínio crítico, ao qual se chegaria, pela síntese dialética, superando a alienação dos trabalhadores.

A outra ruptura foi produzida pelo advento da psicanálise. Freud teria "quebrado" a maior ilusão da modernidade: o agir racional estaria indefectivelmente contaminado pela pulsão de morte: o homem, como sujeito de carência, jamais poderia alcançar o desejado a não ser encarnado em objetos parciais e transitórios. O mundo da razão está contaminado e compelido à reiteração: “Si todos los hombres piensan (...) tratar su subjetividad, su aprehensión del mundo como un simple velo a desgarrar para acceder a la visión objetiva y unívoca de un mundo de verdades fue uno de los errores fundamentales de la modernidad (...) cuando se elimina la subjetividad de un ser, es el ser mismo lo que uno elimina" (Benasayag \& Charlton, 1993:26)

Na teoria geral da administração (TGA), a lógica predominante é a da adaptação dos sujeitos à organização e o controle maquilado dos sujeitos pela organização. As instituições teriam vindo ao mundo não para melhorar a vida dos homens, mas para serem eficientes. Quando, na equação eficácia/ eficiência, a ênfase se coloca puramente nesta última, desloca-se a discussão dos fins para os meios em si. Localizamos aí o efeito colonizador da razão instrumental.

Ao avaliarmos que o senso comum é colonizado pelo agir instrumental, pretendemos exercer o raciocínio crítico. Propomos uma reflexão acerca do novo Planejamento para entidades públicas, sejam elas estatais ou não. Ainda que essas entidades trabalhem reproduzindo a lógica das entidades privadas (eficiência/ dominação), mesmo assim, pensamos que é nelas que o pólo contra-hegemônico (eficácia/ realização pessoal) pode, se estimulado, aparecer com mais facilidade: “En general la razón instrumental es la que se halla al servicio dealgún otro tipo de razón que se estima principal; según el lo, la razón instrumental es ancillar y subordinada a una razón 'sustantiva' o 'substancial'(...) parece que la razón instrumental sea un 'saber cómo' a diferencia de un 'saber qué.'" (Ferrater-Mora, 1994:3010).

Como planejadores contemporâneos, temos responsabilidades. É demanda freqüente das equipes de saúde a de um assessor de planejamento para organizar o "como fazer". Freqüentemente, enquanto técnicos de planejamento, chegamos para instrumentalizar um "saber como" sem interrogar as finalidades estabelecidas. Nesses casos, em nome dos métodos prontos, os sujeitos são sacrificados. Defendemos que, em Planejamento, cabe enfatizar a necessidade de colocar "o que fazer" em análise, pois este é sempre anterior ao "como fazer". E este "o que fazer" não é dado a priori. Deve ser a primeira construção do grupo, um esforço que contribuiria para a constituição da identidade do grupo (Onocko, 1998). Este olhar pode alargar o campo do Planejamento. Por outro lado, enfrentando problemas do dia-a-dia dos serviços, é freqüente encontrar pessoas bem intencionadas com pouquíssimos recursos técnicos. Eficácia zero. Neste ponto é que ressaltamos a responsabilidade dos planejadores, oferecendo competência técnica para instrumentalizar as equipes em relação aos meios.

\section{Análise dos autores}

De acordo com nossa análise, a produção de teorias e métodos de planejamento estratégico em saúde dos autores investigados desenvolveu-se em, pelo menos, quatro linhas diferen- 
tes de acordo com o enfoque predominante, a saber:

- O resgate da potencialidade comunicativa do Planejamento Estratégico, empreendido por autores da Escola Nacional de Saúde Pública do Rio de Janeiro, em especial Javier Uribe Rivera e Edmundo Gallo.

- A ênfase no subsídio do Planejamento Estratégico para a gestão democrática, que caracteriza os trabalhos de, entre outros, Emerson Merhy e Gastão Campos, do Departamento de Medicina Preventiva e Social da Universidade Estadual de Campinas.

- O aprimoramento de uma técnica de Planejamento de Luiz Carlos de Oliveira Cecílio, do Departamento de Medicina Preventiva e Social da Universidade Estadual de Campinas.

- O esclarecimento do Planejamento em relação às teorias da complexidade em voga, empreendido, de modo destacado, por Adolfo Chorny, da Escola Nacional de Saúde Pública do Rio de Janeiro.

Planejamento como meio

da ação comunicativa

A importante contribuição de Rivera para a área de Planejamento em saúde caracteriza-se pela preocupação em ligar os conteúdos do planejamento a uma reflexão filosófico-epistemológica (Rivera, 1989). Ele aproxima, fundamentalmente, a Teoria do Agir Comunicativo de Habermas à área de Planejamento, visando quebrar a instrumentalidade exacerbada de certos métodos.

No texto O Planejamento situacional; uma anál ise reconstrutiva (Rivera, 1992), a tarefa desenvolvida por Rivera é exaustiva. Ele propõe um contraponto teórico entre o Agir Comunicativo e o Planejamento Estratégico Situacional (PES). A partir dessa perspectiva teórica, questiona o PES de Carlos Matus, denunciando o determinismo que o autor chileno atribui à estrutura econômica, o poder determinante da estrutura técnica e o rigor explicativo de "contornos pragmáticos" (Rivera, 1989:53). Diz ele: “(...) parece que na ânsia de uma estruturação, a proposta matusiana exacerba as pretensões controlistas do planejamento e o aproxi ma de uma abordagem objetivista. Isto fica em evidência quando a comunicação é sublinhada em uma perspectiva um pouco instrumental" (Rivera, 1989:90). Ressalta ainda que há “(...) ne cessi dade do planejamento situacional revalorizar as estratégi as de negoci ação e de cooperação, em prol da legitimidade dos planos. Isto implica assumir uma perspectiva mais descentralizada de mundo, trazendo à tona o mundo social dos atores para além da fria compreensão do planejamento enquanto tecnologia (...)" (Rivera, 1989:89).

Na fase de formulação operacional, contudo, Rivera parece querer conciliar a teoria da comunicação com o método proposto por Matus. Assim, para ele,“(...) (a intenção dos atores) deve ser perquirida à luz da ideologia, da história social, da inserção material e das predisposi ções pessoais dos atores (das personali dades como acumulações)" (Rivera, 1989:75).

O trabalho de Rivera (1989) traz grandes contribuições do ponto de vista da crítica e alguns questionamentos fundamentais que, acreditamos, devem ser ressaltados neste fim de século. Entretanto nossa leitura de seu trabal ho constata que ele está interessado, ainda nesse trabalho, numa reconstrução do formato metodológico matusiano. Assim, a análise dos sujeitos acaba repetindo a determinação matusiana: os sujeitos determinados, as personalidades como "acúmulos" e os sujeitos como "possuídos".

Gallo (1992), em sua obra Razão, poder e política para repensar o planejamento, busca conformações históricas para explicar as relações entre Estado, sociedade, razão e poder. Rastreia as raízes dessas relações desde os gregos até chegar às concepções modernas de Estado. "Fecha-se o cicl o colonizador: a economia e o subsistema estatal diagnosticam, delimitam e definem os caminhos sociais. O resultado é a monetarização e a burocratização do mundo vivido; é o bloqueio das ações comunicativas e a despolitização da sociedade; éa impossibilidade desta definir suas normas autonomamente, de se tornar sociedade instituinte. É a derrota da interação ea vitória da técnica" (Gallo, 1992: 32). O autor faz uma crítica do agir instrumental e de sua colonização da vida.

Ao chegar à crítica do planejamento, esse autor resgata outra crítica - a de Castoriardis em relação à impossibilidade de separação total entre meios e fins. Sem dúvida, Gallo conhece bem o problema de subsumir o planejamento a uma mera questão técnica, formal.

Nas formulações finais, defende: “(...) é essencial para quea humanidadecaminheem direção ao seu interesse maior: sua emanci pação enquanto espécietanto das limitações quea natureza Ihe coloca - ao desenvolver sua racionalidade instrumental - quanto das formas derepressão social - através da racionalidade comunicativa." (Gallo, 1992:33). Consideramos que a humanidade não se liberta das limitações da natureza apenas por meio da racionalidade instrumental; nem tampouco concordamos que as formas de repressão social possam acabar pu- 
ramente através da racionali dade comunicativa. Esse tipo de armadilha é o maior triunfo da razão instrumental, pois ela pretende que uma única racionalidade dê conta de todas as ordens de problemas.

O planejamento como subsídio da gestão democrática e das mudanças

Na obra de Campos (1989), o Planejamento aparece somente como método alternativo para racionalizar e adequar estruturas e equipamentos, colocando-os a serviço de novo modelo assistencial. O Planejamento está vinculado à questão da instituição de modelo inovador de gestão. Campos está próximo de Testa e de outros intelectuais latino-americanos que viram no Planejamento uma ferramenta capaz de opor-se a que as leis do mercado sejam as únicas ordenadoras dos sistemas médico-sanitários. Além disso, para ele, os planos deveriam operacionalizar sínteses entre as diretrizes de eficiência e as de eficácia; e entre a saúde pública (prática mais coletiva) e o atendimento médico individual (baseado na clínica médica). Campos espera que o Planejamento seja incorporado ao debate sanitário brasileiro e o resgata como instrumento capaz de promover mudanças, fazendo apelo a sua dimensão teleológica (Campos, 1989).

Pode-se afirmar que, além dessas expectativas, e a de que o Planejamento possa servir como setting para organizar uma gestão mais democrática e participativa, Campos não tem mais demandas para o Planejamento em Saúde. Para ele, o Planejamento é mais um item da gestão, ao contrário de Matus, para quem a gestão é item do Planejamento (Matus, 1993). Essa inversão faz diferença, pois, para Campos, haveria gestão ainda que sem Planejamento, mas não poderia haver Planejamento sem gestão. A questão nuclear em toda a obra desse autor é a de como utilizar o instrumental da gestão para propiciar a construção de sujeitos mais livres e criativos, comprometidos com visão de mundo mais solidária e com o resgate do valor de uso do trabalho (Campos, 1992).

Em textos posteriores, a questão metodológica é revalorizada e, na procura de caminhos operacionais, abre-se o campo do Planejamento a outras disciplinas: “Do ponto de vista teórico (...) temos nos apoiado criticamente, basicamente reservando-nos o direito de reel aboração (...), deGramsci ao Agir comunicativo deHabermas, do planejamento estratégi co às aval iações de desempenho, em tudo temos buscado instrumentos úteis ao sucesso de proj etos (...). Ultimamente, temos valorizado o acervo já acumulado pel os movimentos de psi coterapia eanálise ins- titucional (...). Talvez devêssemos nos apropriar de vários destes ensinamentos (...) imagino que todo gerente, coordenador ou integrante de equi pes de saúde, deveria receber formação eser orientado para operar com esses conhecimentos no dia-a-dia" (Campos, 1994:47).

Preocupando-se com a possibilidade de que a instrumentali dade exacerbada venha a transformar-se em "problema das nossas soluções", denuncia: "Comumente, o planejamento não consegue perceber que o social nunca é só uma abstração estatística, mas quetambém se encarna no doente e em sua doença (...)" (Campos, 1994:60). O Planejamento aparece-Ihe como recurso, mais um, não o único nem o principal, inclusive com problemas.

As principais contribuições teóricas de Campos à área de Planejamento são: ter mostrado a necessidade de abertura para o campo subjetivo e as disciplinas que o abordam, para além das propostas metodológicas prontas; e haver ressaltado que o resgate da função teleológica está indefectivelmente ligado à questão da eficácia, e esta, à produção de valor de uso.

Merhy (1995), em Planejamento como tecnologia de gestão: tendências e debates do planejamento em saúde no Brasil, busca uma tipologia das configurações do Planejamento como tecnologia da ação. Descreve três situações básicas (Merhy, 1995:119):

a) “O planejamento como instrumento/atividade dos processos de gestão das organizações, tendo em vista que nestas ocorrem processos detrabal ho."

b) "O planejamento como prática social transformadora, tendo em vista a determinação de novas rel ações sociais."

c) “O planejamento como método de ação governamental, tendo em vista a produção de políticas."

Merhy questiona o uso do Planejamento nos regimes socialistas pois, “(...) tentar construir uma tecnologia de governar o processo histórico desembocou numa práxis totalitária, enquanto, por outro lado, construir uma tecnologia de governar o processo detrabal ho pode efetivamentelevar a um aumento da eficiência e eficácia dos meios" (Merhy, 1995:125).

A nosso ver, no entanto, o governo planejado do processo de trabal ho, visando a eficiência dos meios, foi muito bem atingido pelo taylorismo. E esse é um modelo paradigmático do que significa "governar o processo detrabalho". O grande desafio estaria colocado no desenvolvimento de algum instrumental que desse conta "de "desgovernar" o processo de trabalho. $O$ processo de trabalho em saúde já está fortemente governado: pelas lógicas dos saberes, 
das formações corporativas, das diretrizes organizacionais etc. (Onocko, 1998). Portanto, o dilema não é como governá-lo, mas como liberá-lo. O próprio Merhy, em trabalhos posteriores, avança nessa questão, propondo ferramentas para promover a liberação do trabalho vivo (Merhy, 1997).

Em relação à produção de políticas, Merhy considera o Planejamento uma "tecnologia de gestão de políticas" (Merhy, 1995:128) e, neste caso, ele é arma do governo. Várias vezes em seu trabalho, Merhy aborda a questão do Planejamento como ferramenta governamental. Contudo, pensamos que o Planejamento também pode vir a instrumentalizar para a ação grupos que não estão necessariamente no governo.

Esse autor não abre mão do agir racional, mas está pensando em múltiplas e não em racionalidade única. Merhy alarga o campo do Planejamento, parecendo, em algumas passagens, que até o dilui, confundindo-o ora com a práxis política ora com a gestão: “Nos casos em que a gestão da política se torna o campo do planejamento (...) a dimensão instrumental do planejamento cedelugar à lógica da política e da conformação histórica dos processos institucionais (...). Desse modo, todos os métodos que procuram impor-se aos instituintes, ambicionando ser em si um instituinte, acabam configurando-se como processos prescriptivos/normatizadores (...)" (Merhy, 1997:148).

Desta maneira, para ser instituinte de mudanças, o Planejamento deveria acabar com os métodos, uma proposta que dificulta construir certa instrumentalidade. Merhy não está preocupado com isto, o que ele quer é desconstruir a visão determinista e fechada do agir instrumental, representado pelas várias correntes de Planejamento que analisa. É essa a sua maior contribuição teórica.

\section{O planejamento como técnica}

Possuir alguma técnica - "Maneira, jeito ou habilidade especial de executar ou fazer algo" (Ferreira, 1997) - parece ser o centro da questão, quando se pensa o problema de certa instrumentalidade.

Entre os autores revisados por nós, foi Cecílio (1997) quem demonstrou maior preocupação em superar os impasses colocados à aplicação sistemática de técnicas de Planejamento. O seu objetivo: manter al gum rigor metodológico, tornando, ao mesmo tempo, acessível ao maior número de pessoas os segredos do Planejamento. Em Uma si stematização e discussão de tecnologia leve da planejamento estratégi co aplicada ao setor governamental, Ce- cílio (1997), sistematiza e divulga seu método, desenvolvido em longos anos de experiência.

Esse autor sugere nova tecnologia de planejamento: "PES modificado ou ZOOP (sigla alemã "Zi el orienti erte Projektplanung" - Planificação de Projetos orientada a objetivos) enriqueci do com PES", cujo desenvolvimento visa dar conta: “(do) tempo como recurso escasso dos dirigentes e da necessi dade de tornar acessível o manuseio detais tecnologias a um número crescente de pessoas (...)" (Cecílio, 1997:152). Cecílio descreve o modo como desenvolve seu trabal ho de planejador. Revela suas fontes (PES, ZOOP) e fundamenta a escolha de seu recorte.

Criticamos, todavia, o recorte do momento explicativo do PES, que Cecílio substitui pela árvore explicativa do ZOOP, pois, a nosso ver, perde-se a etapa mais complexa e demorada do método, mas também a mais rica em crítica e potencialidade de construção de uma compreensão do mundo para além da linearidade do senso comum (Onocko, 1998).

Cecílio recomenda enfaticamente deter-se na descrição cuidadosa dos problemas: “(...) é uma etapa muito importante por duas razões principais: a) para afastar qualquer ambigüidade diante do problema que se quer enfrentar. b) quando bem feita, tem como produto os indicadores que serão utilizados para avaliar os impactos do plano." (Cecílio, 1997:155). Para Matus, eludir a explicação das causas e meramente descrever os problemas é “(...) vício da planificação normativa” (Matus, 1993:245).

Nossa experiência em assessoria de Planejamento leva-nos a preferir pensar os problemas como dados: "como superfície, como momentos mediatizados do conceito que só se preenchem no desdobramento de seu sentido social, histórico, humano (...)" (Horkheimer \& Adorno, 1989:19). Com esse ol har, "afastar (completamente) a ambi güidade" é tarefa impossível, e "quantificar" é uma cristalização muito útil, porém, temporária. Se assumimos que os problemas são dados que precisam ser desdobrados, não podemos concordar com a proposta de, simplesmente, enfatizar a descrição.

Também criticamos a simplificação do momento estratégico, transformando-o em simples análise de controle de recursos e interesse dos atores, já que entendemos esse momento como chave para a constituição da identidade de um grupo. "De fato seria esse o momentochave para a equi pe se confrontar com a pergunta: quem somos? Quem são os outros? Estamos imagi nando o mesmo futuro? Desejamos as mesmas coisas?" (Onocko, 1998:97).

Para Cecílio, “(...) um grupo gerente de projeto não é ator. O ator, no caso, éa autoridade 
que instituiu o grupo" (Cecílio, 1997:153). Leitura instrumental, esmagando os sujeitos: será que se pode supor que um grupo de gerentes funcionaria - de fato - como simples correia de transmissão da vontade, do desejo ou do projeto do chefe-autoridade? Pessoalmente aproximamo-nos mais da idéia de identidade do que da concepção instrumental de ator. Defendemos que todo grupo cria certos padrões de subjetividade a partir das singularidades dos sujeitos que o compõem, e que é a partir desse posicionamento que a tarefa comum se faz possível.

Voltando ao texto de Cecílio, resgatamos seu esforço em construir nova metodologia sistemática; contudo, ressaltamos a fal ta de crítica ao controle advindo da ação instrumental.

O planejamento como meio de intervenção em ambientes complexos

O texto de Chorny (1998) Planificación en saIud: viejas ideas en nuevos ropajes começa pelo resgate do sentido, dos fins do Planejamento: “El propósito dela planificación en salud es la salud (...) Es algo habitualmente aceptado que Ia planificación está referida al futuro" (Chorny, 1998:1). Testa (1997) defende que existem razões "porquê", referidas ao passado, que explicam, e "razões para", referidas ao futuro, que dão motivos para agir. A colocação de Chorny parece óbvia, mas não é. Se o planejamento está referido ao futuro, precisará de "razões para", o que concorda com nosso argumento a respeito de certa razão substantiva, que deveria ser anterior a toda razão instrumental na hora de agir. Chorny (1998) é taxativo quando enuncia os fins: a produção de saúde. Na quase nunca explicitada equação eficiência/ eficácia, ele ressalta a eficácia. Questão praticamente esquecida por alguns planejadores modernos que entraram na pós-modernidade para tornar eficientes (leia-se, baratas) as instituições.

Nesse trabalho, Chorny (1998) repassa toda a tradição de planejamento latino-americano e faz uma análise do cenário futuro, colocando aspectos a serem abordados no planejamento em saúde. Em relação ao passado do planejamento, Chorny honra a tradição, que bem conhece por ter participado do grupo de formuladores nesse campo. O que o separa da maioria dos planejadores é sua aguda capacidade crítica. "Se puede afirmar, sin temor a cometer grandes injusticias, que, actualmente, gran parte de los modelos de planificación en el área dela salud son orientados por el si mpley úni co objetivo de reducir gastos, privil egiando la racionalidad de los medios sobre los fines" (Chorny, 1998: 13). Após contextualizar as teorias da comple- xidade, afirma: “Así, l o que deberia ser un medio, setransformó en un fin" (Chorny, 1998:16).

Para ele, o primeiro objeto de reflexão dos planejadores deverá ser a situação de saúde, o segundo, a dimensão metodológica, e o terceiro, a ação. Em relação à dimensão metodológica, pondera: “(...) La reflexión es substituida por el dogma disfrazado de enunciado científico. Las panaceas mi lagrosas (japonesas, alemanas o decualquier otro lugar del mundo) proponen el éxito fácil para quien sea quelas adopte (...) Para superar los confli ictos generados por estas maneras de ver la realidad (...) es preciso dejar delado los preconceptos y admi tir la interrelación dialéctica entre métodos, suj etos y objetos" (Chorny, 1998:17).

$\mathrm{Na}$ análise dos momentos do planejamento, Chorny ressal ta o momento tático como o momento da programação, resgatando o uso de ferramentas específicas para esse fim. Este é mais um grande esquecimento dos planejadores modernos que não passa despercebido a esse autor. Resumindo, o próprio autor conclui: "Los planificadores (...) seocupan del control de gastos. (...) La innovación se transformó en un fin en sí mismo, no se innova para hacer frente a nuevos problemas o a viejos problemas no resueltos, se crean 'ondas' para hacerse un lugar (...)" (Chorny, 1998:33).

Metodologicamente, Chorny poderia ser considerado um planejador clássico. Todavia, sua aguda visão de mundo permite-Ihe ressaltar a centralidade do conjunto das finalidades para enfrentar os desafios da complexidade. Paradoxo do fim de século: certas leituras clássicas ganham tremenda atualidade.

\section{A título de conclusão}

Nosso foco nos autores concorda com Foucault (1987), quando defende que a pergunta central na interpretação é "quem?". Escolhemos autores que respeitamos e valorizamos pela contribuição ao campo do Planejamento e Gestão em Saúde Coletiva. Nos autores revisados apareceu com muita clareza como o objeto de preocupação de cada um deles foi, simultaneamente, solução e obstáculo para enfrentar os dilemas meios-fins e controle-subj eti vação. Consideramos que a complexidade da tarefa de planejar instituições de saúde exige que esses dilemas sejam enfrentados. Dificilmente, porém, um método ou teoria, sozinho, poderia dar conta de tamanho recado.

Propomos recuperar a idéia de Planejamento como mediação (Onocko, 1998), o que permitiria articular a questão da lógica dos fins 
com a necessária operacionalidade, mas já não mais como tecnologia. Mario Testa (1997) diz que o "saber fazer" em ciências sociais não se incorpora - como no caso das ciências duras como tecnologia, mas como ideologia, e que isto é possível a partir da interpretação histórica (Testa, 1997).

Uma interpretação do Planejamento, nos termos de Foucault (1987), tal como vem sendo pensado e desenvolvido em épocas recentes nas organizações, permite-nos propor mudar a idéia do Planejamento como corpo tecnológico (representado por métodos prontos e acabados) e outorgar-Ihe o papel de modulador de incorporação tecnológica. Assim, o Planejamento poderia ir subsidiando a incorporação de outras ferramentas e técnicas para constituir roteiros, mais ou menos modulados para situações-tipo. Essas situações compreenderiam: momentos dos grupos, momentos da organização, pontos críticos do projeto (seja como vulnerabilidade ou desafio institucional).

Pensar criticamente exige certa capaci dade analítica para apreender o sentido social, histórico e humano de nossas práticas. E jogar com essa capacidade exclui a submissão a receitas prontas. Por que determinado grupo consegue levantar alguns e não outros problemas? O recorte dos problemas, o porquê desse recorte, poderia ser um dos momentos centrais para fazer a ponte entre a capacidade instrumental do Planejamento e a questão de "o que fazer", do sentido, dos fins perseguidos pela al- mejada mudança. Defendemos que o Planejamento pode fazer a mediação entre uma racionalidade crítica, a serviço da liberação das pessoas, e a necessária cota de instrumentalidade operativa (Onocko, 1998).

Assim como Castoriardis (1987) argumenta a não-separabilidade total entre meios e fins, defendemos a não-separabilidade entre o agir racional e o momento subjetivo dos grupos que se preparam para, ou estão em ação. Propomos explorar a idéia de identidade dos grupos, das instituições, como construção possível a partir das identidades individuais, sem apagar as identidades dos sujeitos. Construção que o Planejamento poderia bem subsidiar.

Isso traz à tona a questão de nossa proposta não ser mais a de um método, mas a de um território de composições disciplinares variadas que permitiriam a incorporação tecnológica seqüencial segundo demanda. A intenção é valorizar essa demanda, e conseguir também operacionalizá-la, honrando o compromisso teleológico do Planejamento enquanto atividade, respeitando, sobretudo, a compreensão da vida e a dinâmica dos processos como fluxos, gradientes, sempre provisórios e situacionais.

Foucault (1987) afirma que a interpretação hermenêutica moderna está sempre relacionada com certa terapêutica. Talvez, no fundo, estejamos atrás de uma "cura", a dos males provocados pela aplicação instrumental de certos métodos que acabaram sendo fetichizados por alguns planejadores modernos.

\section{Referências}

BENASAYAG, M. \& CHARLTON, E., 1993. Esta Dulce Certidumbre de lo Peor: Para una Teoría Crítica del Compromiso. Buenos Aires: Ediciones Nueva Visión.

CAMPOS, G. W. S., 1989. Considerações sobre o processo de administração e gerência de serviços de saúde. In: Planejamento sem Normas (E. E. Merhy, G. W. S. Campos \& E. D. Nunes, eds.), pp. 9-32, São Paulo: Editora Hucitec.

CAM POS, G. W. S., 1992. Reforma da Reforma: Repensando a Saúde. São Paulo: Editora Hucitec. 
CAMPOS, G. W. S., 1994. Considerações sobre a arte e a ciência da mudança: Revolução das coisas e reforma das pessoas. O caso da saúde. In: Inventando a Mudança na Saúde(L. C. O. Cecílio, org.), pp. 29-88, São Paulo: Editora Hucitec.

CASTORIARDIS, C., 1987. As Encruzilhadas do Labirinto II. São Paulo: Paz eTerra.

CECÍLIO, L. C. O., 1997. Uma sistematização e discussão de tecnologia leve de planejamento estratégico aplicada ao setor governamental. In: Agir em Saúde (E. Merhy \& R. Onocko, org.), pp. 161-168, São Paulo: Editora Hucitec.

CHORNY, A., 1998. Planificación en salud: Viejas ideas en nuevos ropajes. Cuadernos Médico Sociales (Rosario), 73:5-30.

FERRATER-M ORA, J., 1994. Diccionario de Filosofía. Barcelona: Editorial Ariel.

FERREIRA, A. B. H., 1997. Dicionário Aurélio da Língua Portuguesa. CD-ROM. Rio de Janeiro: Editora Nova Fronteira.

FOUCAULT, M., 1987. Theatrum Philosoficum. São Paulo: Editora Princípio.

GALLO, E., 1992. Razão, poder e política. Para repensar o planejamento. In: Planejamento Criativo: Novos Desafi os em Políticas de Saúde (E. Gallo, J. Rivera \& M. E. Machado, org.), pp. 11-40, Rio de Janeiro: Editora Relume-Dumará.

HORKHEIMER, M. \& ADORNO, T., 1989. Conceito de iluminismo. In: Coleção Os Pensadores. São Paulo: Editora Nova Cultural Ltda.

MATUS, C., 1993. Política, Planejamento \& Governo. Brasília: Instituto de Pesquisa Econômica Aplicada.

MERHY, E. E., 1995. Planejamento como tecnologia de gestão: Tendências e debates do planejamento em saúde no Brasil. In: Razão e Planejamento (E. Gallo, org.), pp. 117-148, São Paulo: Editora Hucitec/Rio de Janeiro: ABRASCO.
MERHY, E. E., 1997. Em busca do tempo perdido: A micropolítica do trabalho vivo. In: Agir em Saúde (E. Merhy \& R. Onocko, org.), pp. 71-112, São Paulo: Editora Hucitec.

MORGAN, G., 1996. Imagens da Organização. São Paulo: Editora Atlas.

ONOCKO, R., 1998. O Planejamento no Divã ou Análise Crítica de uma Ferramenta na Gênese de uma Mudança Institucional. Dissertação de Mestrado, Campinas: Departamento de Medicina Preventiva e Social, Faculdade de Ciências Médicas, Universidade Estadual de Campinas.

PAIM , J. S., 1992. A reforma sanitária e a municipalização. Saúde e Sociedade, 1:29-47.

RIVERA, F. J. U., 1989. Planejamento e Programação em Saúde: Um Enfoque Estratégico. São Paulo: Editora Cortez.

RIVERA, F. J. U., 1992. O planejamento situacional: Uma análise reconstrutiva. In: Planejamento Criativo: Novos Desafios em Políticas de Saúde (E. Gallo, F. J. Rivera \& M. E. Machado, org.), pp. 4192, Rio de Janeiro: Editora Relume-Dumará.

TEIXEIRA, C. F., 1995. O planejamento estratégico situacional em distritos sanitários: Uma experiência no Município de São Paulo. In: Construindo Distritos Sanitários, a Experiência da Cooperação Italiana no Município de São Paulo (C. F. Teixeira \& C. Melo, org.), pp. 69-85, São Paulo: Editora Hucitec/Cooperação Italiana.

TESTA, M., 1997. Saber en Salud. Buenos Aires: Lugar Editorial. 